SANDIA REPORT

8225

SAND97=4. UC-406

Unlimited Release

Printed December 1996
19705331

\title{
A Digital Rykalin Function for Welding
}

\author{
L. A. Bertram
}

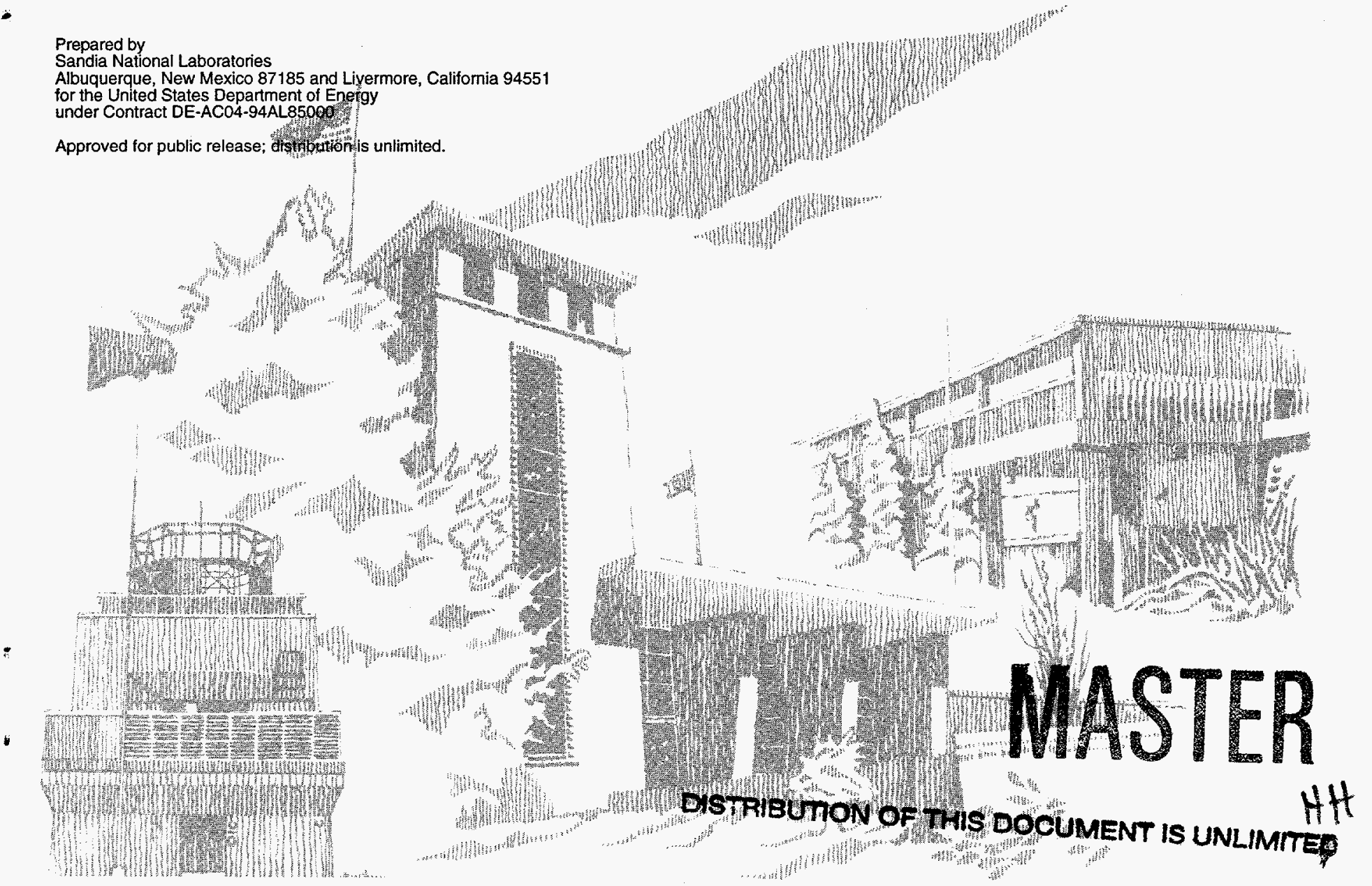


Issued by Sandia National Laboratories, operated for the United States Department of Energy by Sandia Corporation.

NOTICE: This report was prepared as an account of work sponsored by an agency of the United States Government. Neither the United States Government nor any agency thereof, nor any of their employees, nor any of the contractors, subcontractors, or their employees, makes any warranty, express or implied, or assumes any legal liability or responsibility for the accuracy, completeness, or usefulness of any information, apparatus, product, or process disclosed, or represents that its use would not infringe privately owned rights. Reference herein to any specific commercial product, process, or service by trade name, trademark, manufacturer, or otherwise, does not necessarily constitute or imply its endorsement, recommendation, or favoring by the United States Government, any agency thereof or any of their contractors or subcontractors. The views and opinions expressed herein do not necessarily state or reflect those of the United States Government, any agency thereof, or any of their contractors or subcontractors.

This report has been reproduced from the best available copy.

Available to DOE and DOE contractors from:

Office of Scientific and Technical Information

P.O. Box 62

Oak Ridge TN 37831

Prices available from (615) 576-8401, FTS 626-8401.

Available to the public from:

National Technical Information Service

U.S. Department of Commerce

5285 Port Royal Rd.

Springfield, VA 22161 


\section{DISCLAMMER}

Portions of this document may be illegible in electronic image products. Images are produced from the best available original document. 
8225
SAND97-
Unlimited Release

UC-406

Printed December 1996

\title{
A DIGITAL RYKALIN FUNCTION FOR WELDING
}

Lee A. Bertram

Mechanics and Simulation of Manufacturing Processes

Sandia National Laboratories

Livermore, CA 94568

\begin{abstract}
This document outlines the software written to enable a user to evaluate the analytical solutions developed by N.N.Rykalin (1947) for the temperature rise created by moving a heat source of a given power over a workpiece. His solution is extended here so that an arbitrary weld schedule can be prescribed by the user. The inputs are thermophysical properties of the workpiece, and the schedule, in the form of piecewise constant power supply voltage, current and travel speed. The user also specifies the position of the point, and the elapsed time for which the output temperature rise is desired. An optional plot file for the temperature along the travel direction is also provided.
\end{abstract}




\section{NOMENCLATURE}

a

eff

h

$\mathrm{k}$ thermal conductivity $(\mathrm{w} / \mathrm{cm} \mathrm{K})$ at near-melt temperature

$\mathrm{k}_{\mathrm{RT}} \quad$ thermal conductivity at room temperature

$\mathrm{p}$

g

r

$r_{2 \sigma}$

t

ts

"diffusion range"

$\mathrm{x}, \mathrm{y}, \mathrm{z}$

"unit"

W

A

$\mathrm{C}_{\mathrm{p}}$

$\mathbf{G}_{\mathbf{r}}$

$\mathrm{H} \quad$ workpiece thickness $(\mathrm{cm})$

$I_{a} \quad \operatorname{arc~current}(\mathrm{A})$

$\mathrm{P}, \mathrm{P}_{\text {net }} \quad$ weld power into workpiece

$\mathrm{P}_{\mathrm{e}}$ dimensionless parameter for convenient calculation of Rosenthal pools heat flux $\left(\mathrm{W} / \mathrm{cm}^{2}\right)$

radial distance; $r_{\infty}$ is steady pool size $(\mathrm{cm})$ for given $P_{\text {net }}$

"two-sigma" distance for Gaussian heat source

time since weld power-on, sec

time since weld power-on to start of schedule step $\mathrm{k}$

(diffusive penetration distance) $)^{2} /($ at); dimensionless value chosen 4-16

Cartesian coordinates from point weld starts at $t=0$;

$\mathrm{x}$ in travel direction, $\mathrm{y}$ normal to it on surface; $\mathrm{z}$ above workpiece surface.

Units are user-specified in 'weld.inp' file.

Cartesian quasisteady coordinate; distance from weld head at time $t=x-V_{0} t$

cross-sectional area of weld fusion zone

specific heat $(\mathrm{J} / \mathrm{gk})$

geometric ratio of traveling pool cross section to stationary half space

cross section, $\frac{1}{2} \pi r_{\infty}^{2}$

Peclet number based on Gaussian spot size 


$\begin{array}{ll}\mathrm{R}_{\mathrm{y}} & \text { Rykalin number, } \mathrm{V}_{\mathrm{o}} \mathrm{r}_{\infty} /(2 \mathrm{a}) \\ \mathrm{T} & \text { temperature (K) } \\ \mathrm{V}_{\mathrm{a}} & \text { arc voltage }(\mathrm{V}) \\ \mathrm{V}_{0} & \text { travel speed of weld (ipm) } \\ \eta & \sqrt{4 a t / r_{\infty}^{2}} \text { dimensionless time } \\ \eta_{\mathrm{k}} & \sqrt{4 a\left(t-t_{s, k}\right) / r_{\infty, k}^{2}} \text { dimensionless time at schedule segment } \mathrm{k} \\ \eta_{\mathrm{s}} & \sqrt{2 a t / \sigma^{2}} \text { dimensionless time for Gaussian source } \\ \Phi & \text { Kirchhoff thermal variable }=\int k(T) d T \\ \sigma & \text { heating spot size (cm) for Gaussian source } \\ \theta & \text { dimensionless temperature }=\text { (temp rise)/(melt-temp rise) }\end{array}$




\section{A DIGITAL RYKALIN FUNCTION FOR WELDING}

\section{INTRODUCTION}

The ability to conveniently access a thermal model of the welding process can be valuable in weld development and in control of welds in the shop. This convenience is economically provided by solutions in closed form for the heat conduction problem of a traveling heat source, when these sometimes complicated expressions are evaluated in subroutines which take care of the numerical choices encountered in their computation. Such a set of subroutines is provided below, with its use outlined in Section 1. The derivation of the computation starts in section 2 with the concentrated heat source solutions for stationary and moving sources, the latter due to Rosenthal $(1941,1946)$. A technique for superposing such solutions to assess the effect of insulated backside boundary conditions appears as Section 3, and the effects of latent heat and variable thermophysical properties are treated in Section 4. Development of the effects of a time-varying welding schedule comprises section 5. Generalization of the basic heat source solution to the case of distributed (Gaussian) heat sources by Rykalin (1947) is covered in section 6.

\section{USER'S REFERENCE FOR 'ryk' CODE}

The code is the executable RYK.EXE, which reads the files 'sched.dat' and 'weld.inp' to define the input shedule and the position at which the temperature rise is to be calculated, respectively. The 'weld.inp' file also specifies the time (in seconds elapsed since power-on instant). The temperature rise is calculated and written to the file 'ryk.dat, along with the inputs from 'weld.inp'. The object code, 'Ryk.obj' can be linked with other FORTRAN modules to provide the same information to the calling program. For instance, it may be desired to construct another code, to automatically calculate the melt isotherm and display it on screen, as well as write its coordinates into a file .

The user provides the data in 'weld.inp' to define the workpiece, and the data in 'sched.dat' to define the weld process. The content of the files is as follows.

\section{WELD.INP file}

first line: thickness, diameter, room temperature, and unit of length
(in)
(in)
$(\operatorname{deg} F)$
(cm/unit)

second line: hot conductivity, hot diffusivity, liquidus temperature, solidus temperature $(\mathrm{W} / \mathrm{cm}-\mathrm{K}) \quad\left(\mathrm{cm}^{* * 2} 2 / \mathrm{sec}\right) \quad(\operatorname{deg} \mathrm{F}) \quad(\operatorname{deg} \mathrm{F})$
third line:
room- $\mathrm{T}$ conductivit
$(\mathrm{W} / \mathrm{cm}-\mathrm{K})$
(1)
(in)
(1)
fourth line: coordinates $\mathrm{x}, \mathrm{y}, \mathrm{z}$ elapsed time $\mathrm{t}$ (inch) (sec)
solution point definition

The "hot" conductivity and diffusivity are values near melting of the solid.

For an example, suppose a stainless steel tube of 1.25 inch diameter, 0.075 inch thickness is to be welded, in a room at $80 \mathrm{deg} F$. The welder transfers $85 \%$ of its electrical power as heat into the workpiece (see, e.g., Fuerschbach \& Knorovsky 1991), over a spot size of $1 / 8$ inch diameter. The temperature at 10 seconds after the arc is struck is desired, at 
a point $1 / 4$ in along the direction of travel $(x=0.25)$, on the axis of travel $(y=0)$ at a depth of 0.025 in $(z=0.025)$. Then the first line would use unit $=$ inch $=2.54 \mathrm{~cm}$, so the input would read:

$$
\begin{array}{llll}
0.0750 \mathrm{E}+00 & 0.1250 \mathrm{E}+01 & 0.8000 \mathrm{E}+02 & 0.2540 \mathrm{E}+01 \\
0.3500 \mathrm{E}+00 & 0.1000 \mathrm{E}-01 & 0.2645 \mathrm{E}+04 & 0.2555 \mathrm{E}+04 \\
0.3500 \mathrm{E}+00 & 0.8500 \mathrm{E}+00 & 0.1250 \mathrm{E}+00 & 0.4000 \mathrm{E}+01 \\
0.2500 \mathrm{E}+00 & 0.0000 \mathrm{E}+00 & 0.0250 \mathrm{E}+00 & 0.1000 \mathrm{E}+02
\end{array}
$$

as will be found in the sample input file 'weld.sam' . The 'diffusion range' parameter is used to specify how far from a heat source any appreciable heating can reach in the elapsed time $t$ since the heating occurred; namely, range $\left.=(\text { (diffusion range })^{*} \mathrm{a}^{*} \mathrm{t}\right)^{1 / 2}$. Beyond this distance, the sources are ignored in computing the heating at $(\mathrm{x}, \mathrm{y}, \mathrm{z})$. For the sample case, diffusion range $=4$ has been used; values up to 16 are plausible when small temperature differences are of interest far from the weld.

When a girth weld is desired, the value for "diameter" will be nonzero (as in the example), while, for a bead-on-plate weld, the user enters a zero for diameter to define the case.

A weld schedule here is a set of values of $\mathrm{N}$ steps, with each step indexed by $\mathrm{k}=$ $1,2, \ldots N$. For each $k$, an end time $t(k)$ is given, measured from the power-on time $t=0$ in seconds. Between times $t(k-1)$ and $t(k)$, the weld power supply provides current $\mathrm{Ia}(\mathrm{k})$ amps at $\mathrm{Va}(\mathrm{k})$ volts, with travel speed $\mathrm{Vo}(\mathrm{k})$ along the bead. Thus, a 'sched.dat' file is $\mathrm{N}+1$ rows of data, starting with $\mathrm{N}$ on the first line, and followed by $\mathrm{N}$ lines with the four values $t(k), \operatorname{Ia}(k), \mathrm{Va}(\mathrm{k}), \mathrm{Vo}(\mathrm{k})$ on each line.

For the example, suppose that this weld is to be carried out consists of a startup at $30 \mathrm{amps}, 10 \mathrm{~V}$ for $1.5 \mathrm{sec}$ stationary heating, followed by $40 \mathrm{~A}$ at $10 \mathrm{~V}$ for 49 seconds with 4 ipm travel speed, and then tapering down in three steps to $25 \mathrm{~A}$ after $58.9 \mathrm{sec}$ of motion, which is power-off time. The schedule is given as 'sched.sam', which contains:

5

$0.1500 \mathrm{E}+01 \quad 0.3000 \mathrm{E}+02 \quad 0.1000 \mathrm{E}+02 \quad 0.0000 \mathrm{E}+00$

$\begin{array}{lllll}0.5050 \mathrm{E}+02 & 0.4000 \mathrm{E}+02 & 0.1000 \mathrm{E}+02 & 0.4000 \mathrm{E}+01\end{array}$

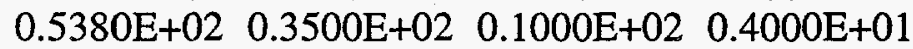

$0.5710 \mathrm{E}+02 \quad 0.3000 \mathrm{E}+02 \quad 0.1000 \mathrm{E}+02 \quad 0.4000 \mathrm{E}+01$

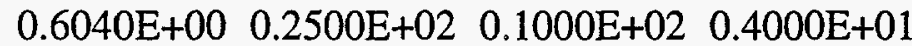




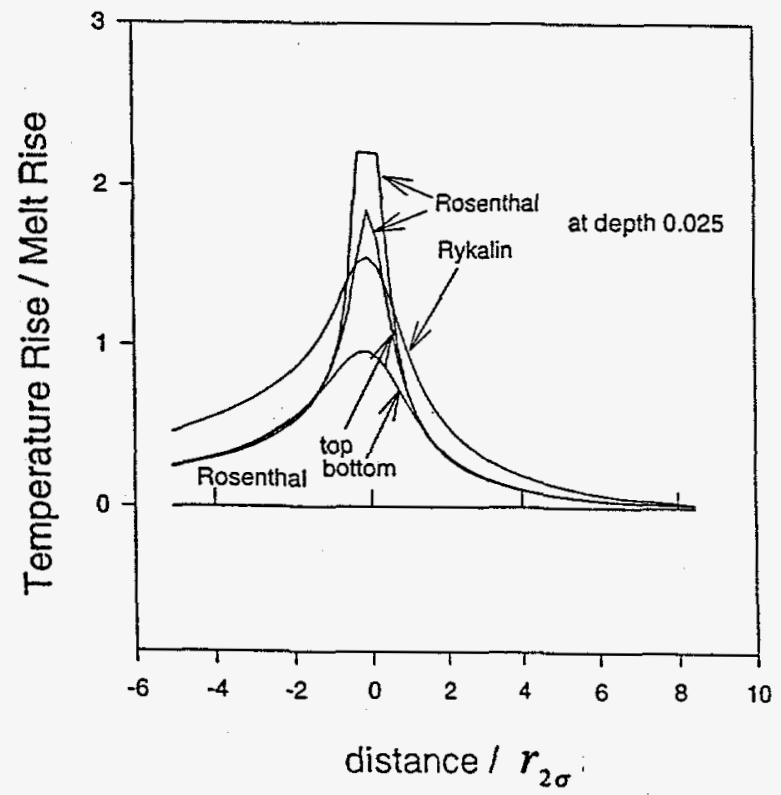

Fig. 1. Plot file output from sample problem defined by inputs in files "weld.sam" and "sched.sam". Temperature rise is shown along a line parallel to travel direction, at depth 0.025 inch below the centerline. Time is $10 \mathrm{sec}$ after power-on. For reference, the Rosenthal (concentrated source) solution is given for the plate top surface (depth $=0$; truncated peak) and the backside (depth $=0.075$ in; lowest curve). The Rykalin solution and Rosenthal solution for the given depth are the two intermediate curves.

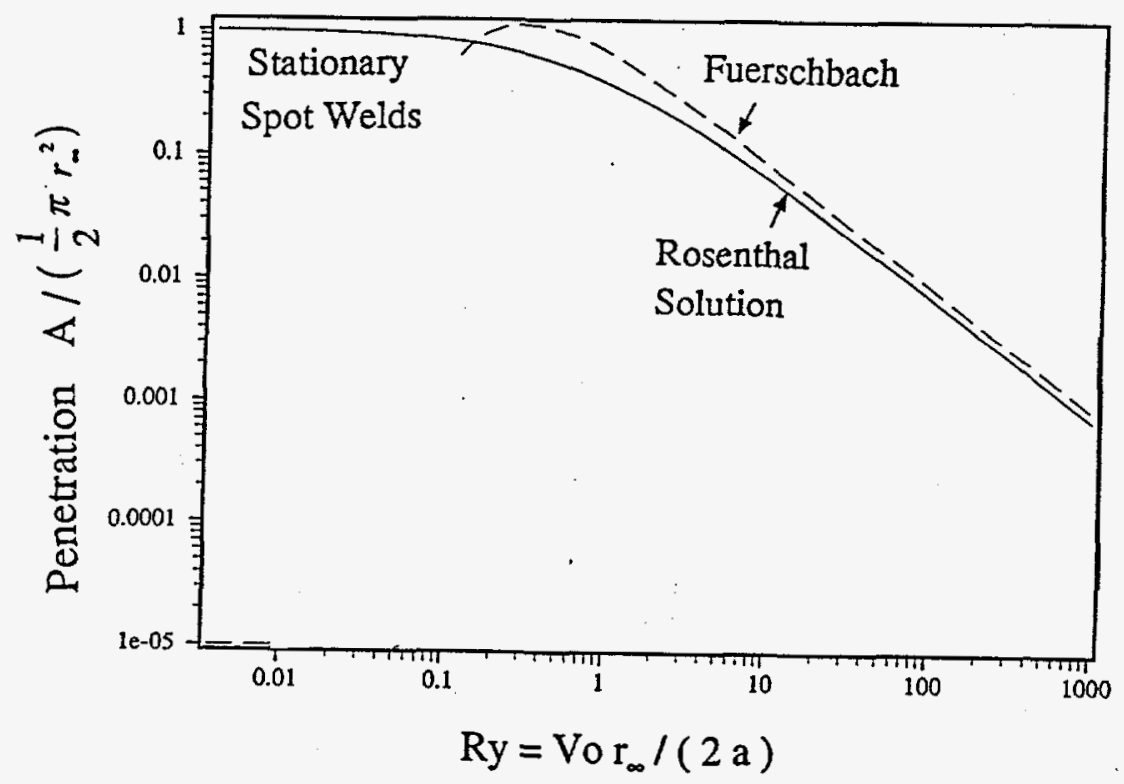

Fig. 2. Penetration of Conductive Welds on a Halfspace. Dimensionless form is changed from Christensen et al., to provide obvious spot weld limit at low travel speed. Penetration parameter Gr is ratio of moving pool transverse area to stationary pool area, and Rykalin number measures travel speed. Laser weld data correlation of Fuerschbach (Eq. 6c) is shown as dashed line, which goes to the fast-travel limit proportional to 1/Ry as Ry gets large. 
Copying the sample files into the input files with commands:

copy weld.sam weld.inp

copy sched.sam sched.inp

prepares the problem for execution. The command,

ryk

then causes the calculation to run, and reports the temperature rise at $(\mathrm{x}, \mathrm{y}, \mathrm{z}, \mathrm{t})$ on screen. After that report, a prompt allows the user to quit (by entering ' $\mathrm{q}$ ') or to generate a temperature profile along the direction of motion, starting from the point $(\mathrm{x}, \mathrm{y}, \mathrm{z})$. To generate the profile, the user responds to the request with an integer and a fraction ( ' $\mathrm{nw}$ ' and ' $d w$ ") to define the number of steps to take in the profile, and the size of the step (as a fraction of the spot size defined in the 'weld.inp' file), respectively. When this entry is made (say, 41,0.2), an output file 'ryk.dat' is written with nw rows of 7 columns: position, Rykalin temperature rise, Rosenthal temperature rise, a set of tick marks at $0.25 *$ unit spacing, and quasisteady Rosenthal top and bottom temperature rises for these positons. These data can then be plotted by any software which plots from the spreadsheet format. The results for the example problem are shown in the plot below, as Fig. 1. A text output file 'ryk.log' is also written, to provide the user with some information about the solution beyond the on-screen results and the plot file. Even more detailed information about the code's workings is given in 'test.log', which the user would rarely consult. There is also an input file 'numer.inp' which defines the internal numerical method, and which the user would rarely modify.

\section{ANALYTICAL SOLUTIONS; PHYSICAL SCALES}

Initially, the workpiece on the surface of which heat is to be applied will be assumed to be a halfspace, with $(\mathrm{x}, \mathrm{y})$ axes on the surface, and $\mathrm{z}$-axis positive above the surface. If a concentrated energy deposition of energy $\delta \mathrm{Q}$ is deposited at the origin, the temperature rise in the halfspace will be the "fundamental solution"

$$
\Delta T=\frac{\delta Q}{(4 \pi a t)^{3 / 2}} e^{-r^{2} / 4 a t}
$$

see, e.g., Carslaw and Jaeger (1959). Here, a is the thermal diffusivity of the halfspace, $a=k /(\rho \mathrm{Cp})$ in terms of thermal conductivity, $k$, and mass density, $\rho$, and specific heat, Cp. The radius $r^{2}$ is given by $r^{2}=x^{2}+y^{2}+z^{2}$. When the thermophysical properties are given as a function of position and time, the heat equation is linear, and solutions for each increment of energy dQ can be simply added to obtain the solution for the sources acting together. Thus, for example, the result of holding a steady power $\mathrm{P}=\mathrm{dQ} / \mathrm{dt}$ at this point would be the temperature rise:

$$
\Delta T=\frac{P}{2 \pi k r} \operatorname{erfc}\left(\frac{r}{\sqrt{4 a t}}\right)
$$

where erfc( ) is the (dimensionless) complementary error function (Abramowitz \& Stegun,1964). After long elapsed times, the argument goes to 0 , and so erfc $(0)=1$ means that the steady solution has a temperature rise which varies like $1 / \mathrm{r}$; in particular, it reaches the melting point $\mathrm{Tm}$ where 


$$
r=r_{\infty}=\frac{P}{2 \pi k \Delta T_{m}}
$$

in terms of the temperature rise $\Delta \mathrm{T}_{\mathrm{m}}=\mathrm{Tm}$ - Tso, where Tso is the initial temperature of the medium. This value $r_{o s}$ is a natural length scale of the problem, namely, the melt pool radius for steady point source heating of the given power applied to the halfspace. When the physical distance $r$ is replaced by the dimensionless variable $r^{\prime}=r / r_{\infty}$ and the second dimensionless variable $\eta=\sqrt{\left(4 a t / r_{\infty}^{2}\right)}$, the "Fourier number", is introduced, the solution (2) takes the simpler form

$$
\theta=\frac{\Delta T}{\Delta T_{m}}=\frac{1}{r} e r f c\left(\frac{r}{\eta}\right)
$$

after the primes are dropped on the dimensionless $r$, and the dimensionless temperature rise $\theta$, measuring the fraction of melt temperature rise, is defined.

If the constant-power source is moving at a constant velocity Vo along the $\mathrm{x}$-axis, then superposition of solutions (1) give the solution. The position $\mathrm{x}$ can be replaced by the distance $\mathrm{w}=\mathrm{x}-$ Vot of the point from the source position, and the (dimensionless) distance $r_{w}{ }^{2}=w^{2}+y^{2}+z^{2}$, scaled by $r_{\infty}$, can be introduced to put this transient solution into the form:

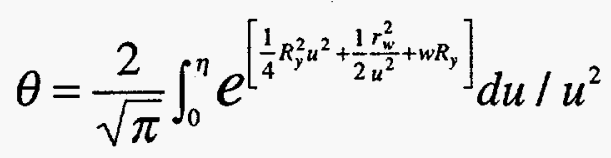

with $\eta=\sqrt{\left(4 a t / r_{\infty}^{2}\right)}$ as before. When time becomes infinite, this has a quasisteady form (usually referred to as the "Rosenthal solution")

$$
\theta=\frac{1}{r_{w}} e^{-R_{y}\left(w+r_{w}\right)}
$$

where the lengths are scaled to $r_{\infty}$. The new parameter appearing here is essentially the quantity which Fuerschbach (1995) has called the 'Rykalin number' Ry $=\operatorname{Vor}_{\infty} /(2 \mathrm{a}$ ), or Christensen et al. (1965) have called the 'operating parameter'. This version of the Rykalin number can be considered to be a Peclet number based on the length $r_{\infty}$ and the travel speed Vo.

The Rosenthal solution (5) defines the temperature history of every point subjected to heating by a concentrated heat source with the constant speed Vo and power Pnet $=$ eff*Ia*Va in terms of a "heating efficiency" eff and the arc current and voltage Ia, Va; see Fuerschbach and Knorovsky (1991) for typical values. Thus, (5) can be used to describe the pool cross section for this case, and Christensen et al. give parametric expressions connecting the pool cross section A to the Rykalin number in terms of a parameter p: 


$$
R_{y}=p e^{p /(1+p)}
$$

and, for the pool size, another expression for the geometric ratio $\mathrm{Gr}=\mathrm{A} /\left(0.5 \pi \mathrm{r}_{\infty}{ }^{2}\right)$ which scales the cross-sectional area of a moving fusion zone to the cross section of the steady spot on the halfspace:

$$
G_{r}=\frac{1+2 p}{(1+p)^{2}} e^{-2 p /(1+p)}
$$

Varying the parameter p over a range of 0.001 to 1000 traces out the curve in Figure 2, where a log-log plot of $(6 a, b)$ is displayed.

Using experimental data, Fuerschbach (1995) developed an expression for $\mathrm{Gr}$ (Ry) which takes the form:

$$
G_{r}=\frac{0.88}{R_{y}} e^{-0.9 /\left(\pi R_{y}\right)}
$$

in the dimensionless variables defined here; this should probably be used only for Ry > 0.2 . Eq. (6c) provides a good approximation to (6) in the case of large Ry, which physically corresponds to the fast moving weld in which penetration area is simply inversely proportional to speed. Note also in Figure 2 that the case of small Ry corresponds to welds with such slow travel speed that their penetration is essentially the same as the stationary spot produced by the same power Pnet. As Christensen et al. showed, the correlation $\mathrm{Gr}$ ( Ry ) provides a reasonable first approximation to the fusion zone size of partial penetration welds, with perhaps a precision of $\pm 50 \%$. One can in fact define "conduction welds" as those for which this procedure gives an acceptable estimate.

\section{FINITE THICKNESS WORKPIECES: IMAGES}

The concentrated source results of the previous section can be improved by introducing the effects of (1) finite workpiece thickness (2) spatial distributions of the heat input (3) inclusion of temperature dependent thermophysical property values, including latent heat of fusion, and (4) inclusion of convective heat transfer in the melt pool, as Rykalin (1947) noted. The first of these had already been treated by Rosenthal (1946), by applying the method of images as outlined below.

Suppose the workpiece is a slab of thickness $\mathrm{H}$. If the backside of the slab is thermally insulated, it has zero flux through it, and the boundary condition on the temperature gradient is

$$
q(x, y, z=H, t)=-k \frac{\partial T}{\partial z}=0
$$

where $\mathrm{k}$ is thermal conductivity of the slab. The $\partial \mathrm{T} / \partial \mathrm{z}=0$ requirement is a symmetry condition, and would result automatically if a second source were to be applied at depth $\mathrm{z}=-2 \mathrm{H}$, when its temperature rise was superposed on the temperature rise of the original source. However, this would also produce a flux through the top surface at $\mathrm{z}=0$, and this (error) flux would have the same distribution as the original source produces in the halfspace at a depth of $-2 \mathrm{H}$. Thus, a second image source at $\mathrm{z}=+2 \mathrm{H}$, would cancel this 
flux at $\mathrm{z}=0$. In doing so, it would introduce an error flux at $\mathrm{z}=-\mathrm{H}$, but one much smaller than before, corresponding to a depth $-4 \mathrm{H}$. The process of cancelling this flux by another source is identical to the process described, and can be continued to build up an infinite series of image sources which satisfy (7) exactly, and have no error flux on the slab topside $\mathrm{z}=0$.

The end result can be written by defining $\theta(x, y, z, t)$ to be the solution for the original heat source traveling along $\mathrm{z}=0$, the first image when $\mathrm{z}$ is replaced by $2 \mathrm{H}-\mathrm{z}$, the second image for

$2 \mathrm{H}+\mathrm{z}$ in place of $\mathrm{z}$, etc. Then the complete solution which satisfies (7) is given by:

$$
\theta_{B C_{\pi}}=\theta(x, y, z, t)+\theta(x, y, 2 H-z, t)+\theta(x, y, 2 H+z, t)+\ldots
$$

This is provided in the code in the subroutine 'botBC()'.

\section{THERMOPHYSICAL PROPERTY VARIATIONS}

Just as (8) can be used to apply boundary conditions more accurately, the venerable Kirchhoff transformation may be exploited to introduce the effects of temperature dependent properties. Note that the full heat conduction equation for a stationary medium is

$$
\rho \frac{\partial h}{\partial t}=\nabla \bullet(k \nabla T)
$$

where $\rho$ is mass density, and $\mathrm{h}$ is enthalpy per unit mass. By defining

$$
d \Phi=k d T \text { or } \Phi=\int_{T_{0}}^{T} k(u) d u
$$

Kirchhoff reduced (9) to the form

$$
\frac{\rho C_{p}}{k} \frac{\partial \Phi}{\partial t}=\nabla^{2} \Phi
$$

By considering the thermal diffusivity to be a function of $\Phi$, this can be written

$$
\frac{\partial \Phi}{\partial t}=a(\Phi) \nabla^{2} \Phi
$$

and all the variability of the coefficients is now captured in a $(\Phi)$. This can include the latent heat of fusion when $\mathrm{Cp}(\mathrm{T})$ is adjusted to account for it. Increasingly accurate solutions to (12) can now be constructed by a Picard-like iterative solution, using the previous iteration to define a function $a(x, y, z, t)$ which preserves the linearity of $(12)$ and allows the superposition needed for the previous sections. The first iterate makes use of the diffusivity near melt conditions, in order to capture the close-in solution as accurately as possible: 


$$
\frac{\partial \Phi_{1}}{\partial t}=a_{0} \nabla^{2} \Phi_{1}
$$

\section{WELD SCHEDULE IMPLEMENTATION}

When time varying currents, voltages or travel speeds are used in real welding situations, the simulation of the effects of the variations can be captured by breaking up the continuous schedule into a finite set of $\mathrm{N}$ constant-condition segments. Duhamel's Theorem assures that such a representation can be arbitrarily close to the actual schedule. Furthermore, the use of digital control tends to result in a discretized schedule even when continuous variation is the ideal. Thus, the simple discrete segment construction has been chosen here.

For the $\mathrm{k}$-th step in the discrete schedule, the heat source is at a position $\mathrm{x}_{\mathrm{h}}(\mathrm{k})$ at the time ts $(\mathrm{k}-1)$ at which the previous step ended; this position becomes the origin for the solution (3). During the step, the source moves along the $x$ direction on the line $y=z=0$, with travel speed Vos $(\mathrm{k})$ and with current Ias $(\mathrm{k})$ and voltage $\operatorname{Vas}(\mathrm{k})$, after being turned on at $\mathrm{t}=\mathrm{ts}(\mathrm{k}-1)$. Efficiency and spot size are taken constant over the whole schedule for the present, but can be allowed to change if practice requires it. The heat source of this k-th step cannot contribute to the heating of the workpiece before it is turned on, so

$$
\theta_{k}=0 \text { for } t<t s(k-1)
$$

This data allows computation of $r_{o}(k)$ and the appropriate $w, \eta$, and Rykalin number Ry (k) for the step. That is, (3) is to be evaluated with

heat source position at t:

$$
x_{h}(t)=x_{h}(k-1)+\operatorname{Vos}(k)(t-t s(k-1))
$$

sample point position:

$$
\begin{aligned}
& w=x-x_{h}(k-1)-\operatorname{Vos}(k)(t-t s(k-1))=x-x_{h}(t) \\
& r_{\infty}(k)=\operatorname{Ias}(k) \operatorname{Vas}(k) \text { eff } /\left(2 \pi k \Delta T_{m}\right) \\
& \eta_{k-1}=\frac{\sqrt{4 a(t-t s(k-1))}}{r_{\infty}(k)} \\
& w_{k-1}=w / r_{\infty}(k) \\
& R y(k)=\operatorname{Vos}(k) r_{\infty}(k) /(2 a)
\end{aligned}
$$

and the solution is then $\theta\left(\eta_{k-1}, w_{k-1}, R y(k)\right)$ for $\operatorname{ts}(k-1)<t$. When the source reaches the end of the step at $t=t s(k)$, it is turned off by superposing a negative source which starts at ts $(\mathrm{k})$ with power $=$ Pnet. This solution has $\mathrm{ts}(\mathrm{k}-1)$ and $\mathrm{xh}(\mathrm{k}-1)$ replaced by $\mathrm{ts}(\mathrm{k})$ and $\mathrm{xh}(\mathrm{k})$ 
respectively in the expressions above, and is denoted by $-\theta\left(\eta_{k}, w_{k}, \operatorname{Ry}(k)\right)$, and is superposed for $t>t s(k)$. In summary, the solution (3) gets a contribution

$$
\begin{array}{cr}
0 . & t<t s(k-1) \\
\theta(k)=\theta\left(\eta_{k-1}, w_{k-1}, R y(k)\right) & t s(k-1)<t \\
\theta\left(\eta_{k-1}, w_{k-1}, R y(k)\right)-\theta\left(\eta_{k}, w_{k}, R y(k)\right) t s(k)<t
\end{array}
$$
distance of

Each of these functions is the result of a diffusion process, which penetrates a

$$
\text { range }=\left[(\text { diffusion range }) a(t-t s(k-1)]^{1 / 2}\right.
$$

by time $t$, and the solution $\theta$ is exponentially small at distances greater than range. Thus, if the sample point has coordinates for which

$$
\text { dist }=\left[(x-x h(k))^{2}+y^{2}+z^{2}\right]^{1 / 2}>\text { range }
$$

holds, the contribution of that source can be neglected. The subroutine sources() applies conditions (13) and (14).

At the sample time $t$ at which the temperature is to be evaluated, not all the sources have been activated--only those with $\mathrm{ts}(\mathrm{k})<\mathrm{t}$ are completed, and the one with ts $(\mathrm{kmax}-1)$ $<\mathrm{t}<\mathrm{ts}(\mathrm{kmax})$ is being carried out. This means that superposition takes the form:

$$
\theta(x, y, z, t)=\sum_{k=1}^{k_{\max }} \theta(k)
$$

This sum (15) is assembled in subroutine addup().

\section{DISTRIBUTED HEAT SOURCES}

A major error built into the approximation (5) is the infinite temperature at the position of the heat source. This can be removed, and the accuracy in the neighborhood improved, by allowing the heat flux boundary condition on the topside $\mathrm{z}=0$ surface to be spread over a region. For a variety of reasons, the Gaussian distribution proves convenient [Rykalin 1947)]:

$$
q(x, y, z=0, t)=-k \frac{\partial T}{\partial z}=\frac{3 P}{\pi r_{2 \sigma}^{2}} e^{\frac{-3 r^{2}}{r_{2 \sigma}^{2}}}
$$

where $r_{2 \sigma}$ is the "two-sigma radius" of the Gaussian function; $P$ is the thermal power being retained in the workpiece. The solution to (12a) for boundary condition (16) on the surface of a halfspace is [ Rykalin (1947) and, e.g., Eagar and Tsai (1986)]: 


$$
\begin{aligned}
\theta & =\frac{2}{\sqrt{\pi}} \int_{0}^{\eta} \frac{e^{-E_{v}}}{v^{2}+s^{2}} d v \\
E_{v} & =\frac{1}{4} R y^{2}\left(v^{2}-s^{2}\right)+\frac{\left(w+\frac{1}{2} s^{2} R y\right)^{2}+y^{2}}{v^{2}+s^{2}}+\frac{z^{2}}{v^{2}}+w R y \\
s & =r_{2 \sigma} /\left(r_{\infty} \sqrt{3}\right)
\end{aligned}
$$

in terms of the new dimensionless spot size variable $s$, in addition to $\eta$ and Ry which appeared already in (8). Variable thermophysical properties and backside boundary conditions are dealt with here exactly as indicated in Sections 3,4 and 5 above.

Another form can be given to (17) by change of variables, namely:

$$
\begin{aligned}
& \theta=\sqrt{\frac{2}{\pi}} \frac{r_{\infty}}{\sigma} \int_{0}^{\eta_{s}} \frac{e^{-\frac{1}{2} E}}{u^{2}+1} d u \\
& E=P e^{2}\left(u^{2}-1\right)+\frac{(w+P e)^{2}+y^{2}}{u^{2}+1}+\frac{z^{2}}{u^{2}}+2 w P e \\
& \eta_{s}=\frac{\sqrt{2 a t}}{\sigma} \quad \sigma=r_{\infty} / \sqrt{6} \quad P e=\frac{V_{0} \sigma}{2 a}
\end{aligned}
$$

where $\eta_{s} \sqrt{\left(2 a t / \sigma^{2}\right)}$. This scaling by $\sigma=r_{2 \sigma} / \sqrt{(6)}$ gives nice forms to the integrand and particularly the exponent, and was used for that reason as the backbone of the subroutines 'setk', 'gee'. The resulting function has the integral as a function of five parameters: $(x, y, z, \eta, P e)$, with coordinates scaled to $\sigma$. The scale is set by the multiplier $r_{\infty} / \sigma$, the only appearance of $r_{\infty}$, which is not known to the user at the outset. All these contribute to making this form the one used, even though it becomes singular as the concentrated heat source condition is approached by taking $\sigma$ going to zero. The $r_{\infty}$ scaling in (14) has all variation in its integral, which depends on ( $w, y, z, \eta, R y, s)$, and with perfectly tame limit as $s-\rightarrow 0$ (which reproduces (6), the concentrated moving heat source transient solution, when $u$ is replaced by $1 / \mathrm{u}$ as the integration dummy). 


\section{SUMMARY}

The code described above provides the ability to evaluate the temperature at any point $\mathrm{n}$ space or time for a slab of finite thickness and known thermophysical properties, when a Gaussian heat source of specified concentration (spot size) is moved along a straight line according to a specified schedule of travel speeds and power settings. For girth welds on tubes the preheating of the "tie-in" zone is assessed automatically, The particular code "ryk" uses this pointwise ability to trace out instantaneous (at specified time t) temperature profiles along lines parallel to the travel directions, at any lateral distance and any depth into the workpiece the user may specify. Sample inputs were given in Section 2 above.

Applications of this capability of fast, computationally simple evaluation of the conductive solutions are many. Among them are

- the ability to make approximate surveys of the effects of the weld parameters on heat histories for particular points in welds,

- the ability to assess the transient development of weld penetration,

- the ability to provide interactive advice to designers in the preliminary design phase for a weld joint,

- the ability to have real time response for model based feedback control of welds,

- the ability to estimate, at real time speeds, pool sizes from given sensor response; i.e., a base for "pseudosensors" of penetration.

Each application would of course require its own output stream, but would be available from the same set of modules provided here.

The modules which comprise the "ryk" code can provide other outputs than the temperature profiles. To obtain other results, it is only necessary to write a module which systematically calls the pointwise function and outputs the desired information.

This conductive code cannot simulate the effects of fluid flow on melt pool transport without additional modules. An appealing way in which such modules might be constructed has been given by Nunes (1983). Other boundary effects (plate edges, etc.) can be treated by the use of images in the manner of Rosenthal (1946) and Rykalin (1947) if desired. 


\section{.}

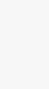

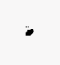

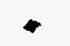

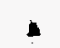

$\bullet$

4 
REFERENCES

Abramowitz, M. and Stegun, I., Handbook of Mathematical Functions, Dover, New York. (1964)

Burgardt, P. and Heiple, C. R., "Weld Penetration Sensitivity to Welding Variables when near Full Joint Penetration," Weld. J. 71,341-s. (1992)

Carslaw, H. S. and Jaeger, J. C., Conduction of Heat in Solids, Oxford University Press, Oxford. (1959)

Christensen, N., Davies, V.de L. and Gjermundsen, K. "Distribution of Temperatures in Arc Welding," Brit. Weld. J. 12,54. (1965)

Eagar, T.W. and Tsai, N.-S,."Temperature Fields Produced by Traveling Distributed Heat Sources," Weld. J. 346-s. (1983)

Fuerschbach, P. W. and Knorovsky, G. A., "A Study of Melting Efficiency in Plasma Arc and Gas Tungsten Arc Welding," Weld. J. 70,287. (1991)

Fuerschbach, P. W., "A Dimensionless Parameter Model for Arc Welding Processes," in Trends in Welding Research, H. Smartt, J. A. Jackson, and S. A. David, eds. TMS, Warrenville, PA. p 493. (1994)

Nunes, A. C., Jr., "An Extended Rosenthal Weld Model," Weld. J. 62 (6), 165-s. (1983)

Rosenthal, D."The Mathematical Theory of Welding and Cutting," Weld. J. 20,220s. (1941)

Rosenthal, D.,"The Theory of Moving Sources of Heat and its Application to Metal Treatments," Trans. ASME, 68,849. (1946)

Rykalin,N.N. Teplovyi Osnovy Svarki-Chast' Pervaya: Protsessy Rasprostraneniya Tela pri Dugovoy Svarkye (The Thermal Basis of Welding-Part I: Diffusive Processes during Arc Welding: in Russian), Acad. Sciences USSR, Moscow. (1947) 
Unlimited Release

Caterpillar, Incorporated

Technical Center-E

Post Office Box 1875

Peoria, IL 61656

Attn: Leo Chuzhoy

EWI

1100 Kinnear Road

Columbus, OH 43212

Attn: David Yapp

Jeffrey S. Crompton

Darren M Barborak

Chris Conrardy

The Ohio State University

Welding Engineering

Columbus, OH 43212

Attn: Prof. R. W Richardson

Stanford University

Lucas MRS Imaging Center

Department of Radiology

Stanford, CA 94305

Attn: Prof. Kim Butts

$\begin{array}{lll}1803 & \text { MS1434 } & \text { J. L. Jellison } \\ 1803 & \text { MS1134 } & \text { F. J. Zanner } \\ 1809 & \text { MS9405 } & \text { D. L. Lindner } \\ 1831 & \text { MS1411 } & \text { M. J. Cieslak } \\ 1833 & \text { MS0367 } & \text { B. K. Damkroger } \\ 1833 & \text { MS0367 } & \text { P. W. Fuerschbach } \\ 1833 & \text { MS0367 } & \text { G. A. Knorovsky } \\ 1833 & \text { MS0367 } & \text { C. V. Robino } \\ 4231 & \text { MS1380 } & \text { D. W. Larson }\end{array}$

8000 MS9001 T. O. Hunter;

Attn: J. B. Wright, 2200 (MS9005)

E. E. Ives, 5200 (MS9006)

M. E. John, 8100 (MS9004)

L. A. West, 8200 (MS9420)

W. J. McLean, 8300 (MS9054)

R. C. Wayne, 8400 (MS9007)

P. N. Smith, 8500 (MS9002)

P. E. Brewer, 8800 (MS9141)

D. L. Crawford, 8900 (MS9003)

8202 MS9405

8204 MS9430

8220 MS9420

8220 MS9420

R. E. Stoltz

L. N. Tallerico

R. G. Hillaire

S. Marburger 
$8240 \quad$ MS9430

8240 MS9430

8240 MS9430

8700 MS9405

J. Brooks

C. H. Cadden

A. J. West

T. M. Dyer;

Attn: M. W. Perra, 8711 (MS9402)

M. I. Baskes, 8712 (MS9403)

J. C. F. Wang, 8713 (MS9403)

G. J. Thomas, 8715 (MS9402)

K. L. Wilson, 8716 (MS9161)

W. G. Wolfer, 8717 (MS9161)

M. R. Birnbaum, 8742 (MS9042)

W. A. Kawahara, 8746 (MS9042)

8713 MS9403

8743 MS9042

8743 MS9405

8743 MS9405

8743 MS9405

9113 MS0835

9113 MS0835

B. E. Mills

M. P. Kanouff

J. F. Lathrop

L. A. Bertram (5)

P. E. Nielan

R. L. Akau

S. E. Gianoulakis

8815 MS9021 Technical Communications Department, 8815 for OSTI (10)

1 $8815 \quad$ MS9021

Technical Communications Department, 8815/Technical Library, 4414 (MS0899)

4414 MS0899 Technical Library (4)

8940-2 MS9018 Central Technical Files (3) 


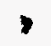

3 